\title{
The Nighttime Distribution of Ozone in the Low-Latitude Mesosphere
}

\author{
By R. G. RoBLE ${ }^{1}$ ) and P. B. HAYs ${ }^{2}$ )
}

\begin{abstract}
The intensity of stars at wavelengths in the Hartley continuum region of ozone has been monitored by the University of Wisconsin stellar photometers aboard the OAO-2 satellite during occultation of the star by the earth's atmosphere. These occultation data have been used to determine the ozone number density profile at the occultation tangent point. The nighttime ozone number density profile has a bulge in its vertical profile with a peak of 1 to $3 \times 10^{8} \mathrm{~cm}^{-3}$ at approximately $83 \mathrm{~km}$ and a minimum near $75 \mathrm{~km}$. The ozone number density at high altitudes varies by as much as a factor of 4 , but does not show any clear seasonal variation or nighttime variation. The retrieved ozone number density profiles define a data envelope that is compared with other nighttime observations of the ozone number density profile and also the results of theoretical models.

Calculations are also presented that illustrate the difference in retrieving the bulge in the ozone number density profile from stellar and solar occultation data.
\end{abstract}

\section{Introduction}

Stellar intensity measurements, in certain ultraviolet atmospheric absorption bands, made by a satellite during occultation of the star by the earth's atmosphere, can be used to obtain the local number density of the absorbing species at the occultation tangent point (HAYs and RoBLE [8-9]). During the past few years the Orbiting Astronomical Observatory (OAO-2) has been used to make these occultation intensity measurements using bright ultraviolet stars (HAYs et al. [12]). The occultation technique is based on classical ultraviolet absorption spectroscopy. The star is the source of ultraviolet light and the stellar photometers aboard the OAO-2 satellite are the detectors. The atmosphere between the star and the detectors acts as the absorption cell. During the occultation process, the stellar light passes through progressively denser regions of the atmosphere and the ultraviolet light is absorbed due to the strong absorption features of certain atmospheric gases. The basic measurement is thus the stellar intensity as a function of time, but by knowing the star's position and the satellite orbital elements, the intensity is related to the tangent ray height of the occulting star. If absorption is due to a single species, the normalized stellar intensity is directly related to the tangential

\footnotetext{
1) National Center for Atmospheric Research, Boulder, Colorado 80302. (The National Center for Atmospheric Research is sponsored by the National Science Foundation.)

${ }^{2}$ ) Department of Atmospheric and Oceanic Sciences, University of Michigan, Ann Arbor, Michigan 48104.
} 
column number density of the absorbing species through Beer's Law (HAYS and ROBLE [10]). The data giving the tangential column number density as a function of tangent ray height are directly inverted, using the technique described by RoBLE and HaYs [22] to obtain the local number density profile of the absorbing species at the occultation tangent point.

Occultation measurements made in the Schumann-Runge continuum of molecular oxygen near $1500 \AA$ have been used to obtain the molecular oxygen number density profile in the lower thermosphere. These measurements have been discussed by HAYs and RoBLE [10]. The nighttime number density profile of ozone in the mesosphere has also been determined from stellar intensity measurements made in the Hartley continuum region of ozone near $2500 \AA$. The results of these measurements are discussed by HAYs and RoBLE [11].

In this paper, we compare the results of the OAO-2 ozone measurements with theory and other nighttime ozone measurements. We also present the results of a single occultation scan and discuss the difference in retrieving the ozone number density bulge near $80 \mathrm{~km}$ from solar and stellar occultation data.

\section{Stellar occultation scan}

The ozone and molecular oxygen absorption cross sections and the transmission function of the various uitraviolet filters used with the OAO-2 stellar photometers for the occultation measurements are shown in Fig. 1. Filter (4-1) is located in the Schumann-Runge continuum region of molecular oxygen and is used to obtain the molecular oxygen number density in the lower thermosphere. Filters (2-5) and (3-2) are in the Hartley continuum region of ozone and are used to obtain the ozone number density profile in the mesosphere. Filter (1-4) is used to measure the ozone number density in the stratosphere.

The results presented in this paper were determined from occultation data obtained by the OAO-2 stellar photometers using filters (2-5) and (3-2). HAYS and ROBLE [9] have shown that stellar ultraviolet light near $2500 \AA$ is primarily absorbed by ozone in the earth's atmosphere and stellar occultation measurements within this wavelength region can be used to obtain the ozone number density profile in the 60 to $100 \mathrm{~km}$ altitude interval. In the lower portion of the altitude interval rayleigh scattering and molecular oxygen absorption in the Herzberg continuum have small contributions to the total attenuation. These contributions are eliminated from the data as discussed by HAYs and ROBLE [10].

The intensity spectrum of the star above the earth's atmosphere is measured by an ultraviolet spectrometer aboard the OAO-2 satellite. A typical star spectrum, obtained on orbit 12178 on 3 April, 1971, is shown in Fig. 2. The solar spectrum is also shown in Fig. 2 for comparison. The normalized signal of this star, measured during occultation using the OAO-2 stellar photometer with filter (3-2), is shown in Fig. 3a. Below $100 \mathrm{~km}$ the signal decreases due to absorption by ozone. The decrease in the signal continues 
until an altitude of about $83 \mathrm{~km}$, then a slight increase in the signal occurs reaching a maximum around $75 \mathrm{~km}$. Below $75 \mathrm{~km}$ the signal decreases again until occultation near $45 \mathrm{~km}$. The ozone number density profile at the occultation tangent point is obtained from the intensity data using the inversion scheme described by ROBLE and HAYs [22]

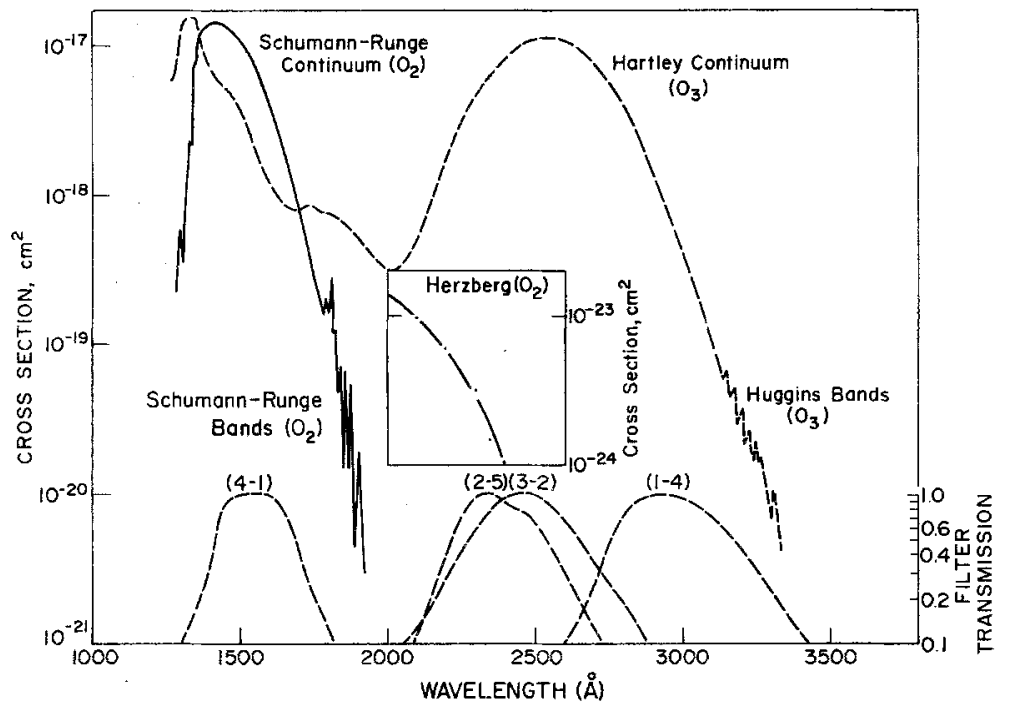

Figure 1

Absorption cross-sections for molecular oxygen and ozone. The dashed curves give the transmission functions for the filters used with the OAO-2 stellar photometers. Filter (4-1) is used to obtain the molecular oxygen number density in the lower thermosphere and Filters (2-5), (3-2) and (1-4) are used to determine the ozone number density in the mesosphere

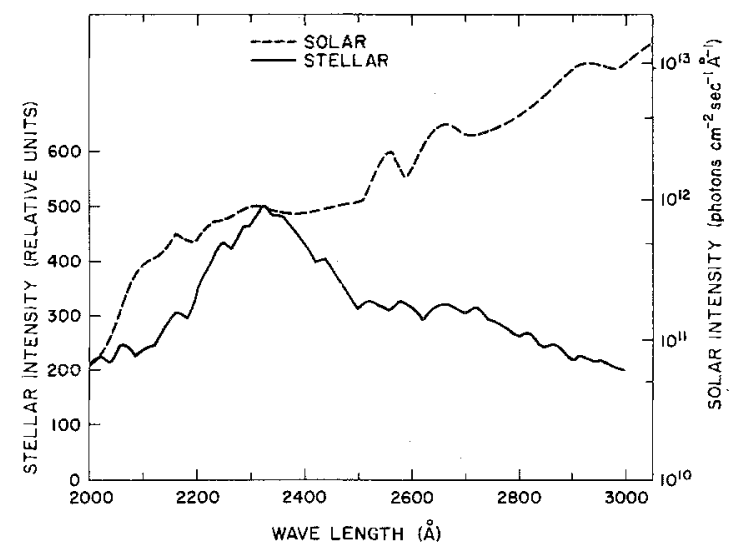

Figure 2

Solid curve is the stellar intensity as a function of wavelength measured by the OAO-2 spectrometer prior to occultation on orbit 12178. This star was used to obtain the occultation data shown in Fig. 3 . The dashed curve is the solar spectrum obtained from ACKERMAN [1] 
and HaYs and Roble [10] and is shown in Fig. 3b. The dip in the normalized intensity curve near $80 \mathrm{~km}$, shown in Fig. 3a, is due to a bulge in the ozone number density distribution at that altitude. The peak ozone number density at the bulge is $3 \times 10^{8} \mathrm{~cm}^{-3}$ at $83 \mathrm{~km}$. The minimum occurs near $73 \mathrm{~km}$, however, the magnitude of the number density at that altitude is difficult to determine. A complete discussion of accuracy of the inversion scheme and an analysis of errors in the occultation measurements have been given by ROBLE and HAYS [22].
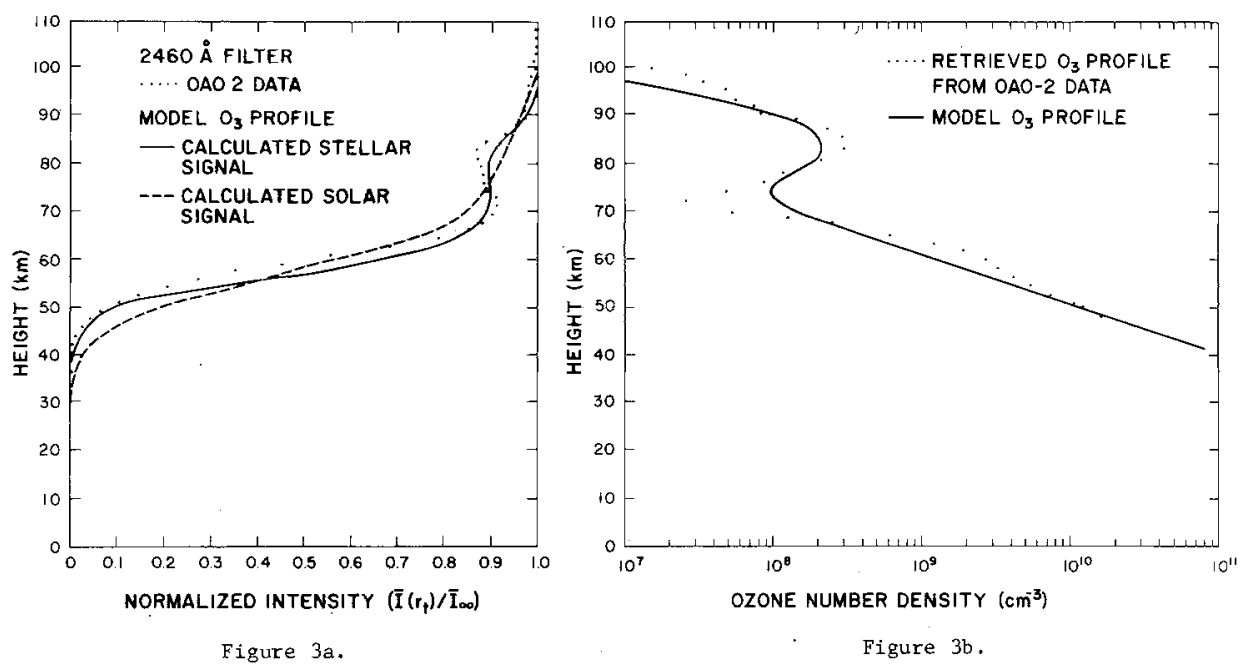

Figure 3

a) The dots give the normalized intensity as a function of tangent ray height measured by the OAO-2 stellar photometers using the $2460 \AA$ filter. The geographic position of the occultation tangent point is $35^{\circ} \mathrm{N}, 114^{\circ} \mathrm{W}$ and time is $22.33 \mathrm{LMT}$ on 3 April, 1971 . The solid and dashed curves are the calculated normalized intensities for a stellar and solar occultation respectively using the model ozone profile in Fig. 3b. b) The dots give the retrieved ozone number density profile from the $\mathrm{OAO}-2$ occultation data shown in Fig. 3a. The solid curve is the model ozone number density profile used to calculate the stellar and solar intensity profiles in Fig. 3a

\section{Stellar vs. solar occultation}

The ozone number density profile has also been determined from solar occultation measurements made from a satellite (RAWCLIFFE et al. [20], MiLLER and STEWART, [18]). If the intensity from the entire solar disk is used during occultation the effect of the finite size of the sun must be considered in analyzing the data. In this section we examine whether the bulge in the ozone number density near $80 \mathrm{~km}$ can be determined from solar occultation measurements when the entire solar disk is used as the source. For simplicity a model of the ozone number density profile is used in these calculations. The ozone profile is approximated by a sum of gaussian and exponential functions (ROBLE and $\mathrm{HAYs}_{\mathrm{A}}$ [22]) and the profile is shown in Fig. 3b. The normalized intensity calculations 
for a stellar occultation, using OAO-2 filter (3-2), are shown in Fig. 3a. The intensity calculations for the broadband filter require a wavelength integration over the effective passband of the filter (HAYS and RoBLE [10]). Therefore, we use the stellar spectrum, shown in Fig. 2, the ozone absorption cross-section and the filter transmission functions, shown in Fig. 1, to calculate the normalized occultation signal for the model ozone number density distribution. The calculated normalized intensity profile is shown in Fig. 3a and it has approximately the same shape as the OAO-2 occultation data. The dip in the intensity curve defines the bulge in the ozone number density profile.

For a solar occultation, the finite size of the sun must be considered because the solar energy emitted from different portions of the solar disk is transmitted through the

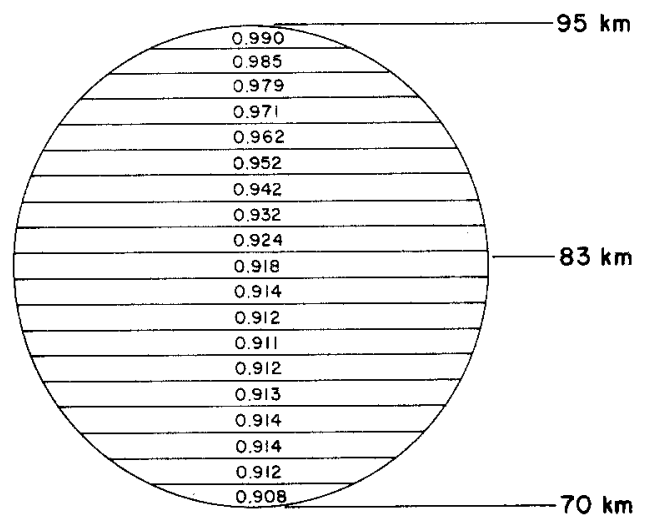

Figure 4

The calculated normalized intensity distribution across the solar disk at a tangent ray height of $83 \mathrm{~km}$. The satellite altitude at occultation is $715 \mathrm{~km}$. The OAO-2 filter transmission function for the $2460 \AA$ filter is used in the calculations. The tangent ray heights for the upper and lower solar limbs are also given in the figure

earth's atmosphere at different tangent ray heights. The normalized intensity for a solar occultation is calculated using the technique of ROBLE and NORTON [23] and is shown in Fig. 3a. For these calculations we used the solar energy spectrum, shown in Fig. 2, the ozone cross-section and the filter (3-2) transmission function shown in Fig. 1. The dip in the intensity curve that occurs in the stellar occultation case does not appear in the solar occultation case. From normal satellite altitudes the tangent ray heights of the upper and lower limb of the solar disk are separated by approximately $25 \mathrm{~km}$. Therefore a smearing of the intensity variation caused by the bulge in the ozone number density profile occurs when the entire solar disk is used during occultation and a dip in the intensity profile is not evident. The calculated normalized intensity variation across the solar disk at a tangent ray height of $83 \mathrm{~km}$ for the center of the solar disk is shown in Fig. 4. The tangent ray height of the upper limb is $95 \mathrm{~km}$ and the lower limb is $70 \mathrm{~km}$. The intensity variation caused by the bulge in the ozone number density profile at $83 \mathrm{~km}$ 
occurs near the center of the solar disk. The intensity structure across the solar disk is not evident when the overall intensity from the entire solar disk is measured during occultation. In theory, the structure in the ozone number density profile can be retrieved from solar occultation data using the entire solar disk, with an iterative technique. However, in practice, the iterative scheme is difficult to use especially in the presence of statistical noise. Better results would be obtained if a small portion of the solar disk is used for the solar occultation measurements.

\section{Comparison of results}

The ozone number density profiles from twelve stellar occultations have been presented by HAYS and ROBLE [11]. The measurements indicate that mesospheric ozone has a variation of as much as a factor of 4 at high altitudes, but does not show any clear

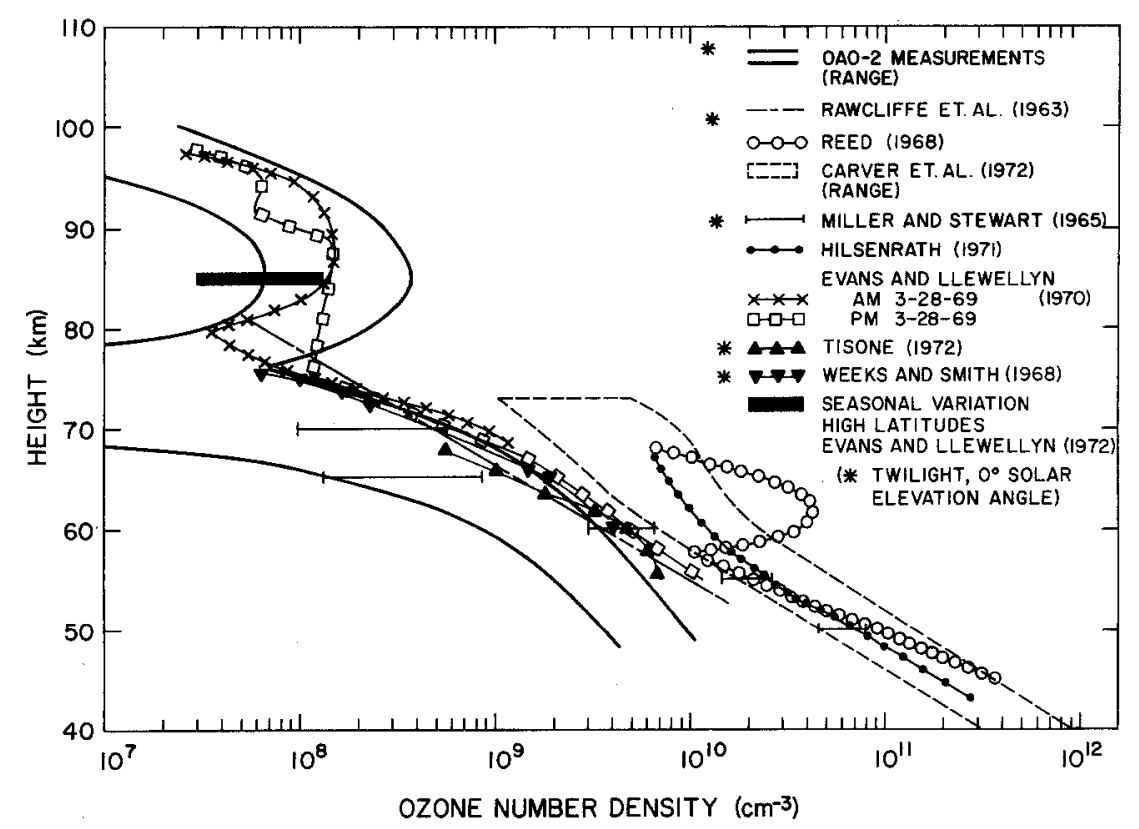

Figure 5

Comparison of the OAO-2 ozone data envelope with the nighttime ozone number density profiles determined by various observers

seasonal or nighttime variation. A slight increase in the altitude of the bulge in the ozone number density profile appears to be associated with increasing latitude. These measurements plus a few additional ones are used to define an envelope representing the ozone number density profiles determined from the OAO-2 stellar occultation measurements. The envelope is shown in Fig. 5 along with nighttime and twilight ozone profiles 
determined by other experimenters. At high alticudes there is good agreement with the ozone number density profiles determined by the OAO-2 satellite and the profiles deduced by EVANS and LLEWELLYN [5-6]. Between 60 and $75 \mathrm{~km}$, the data of EVANS and Llewellyn [5-6], Evans et al. [7], Weaks and Smith [26], Miller and Stewart [18], TisONE [25] and RAWCLIFFE et al. [20] are clustered along the upper limb of the OAO-2 ozone data envelope. Below $60 \mathrm{~km}$, the OAO-2 ozone data envelope does not agree with the results of CARVER et al. [3-4], ReED [21] and HILSENRATH [14]. This departure from the other observations is probably due to the difficulty of retrieving the ozone number

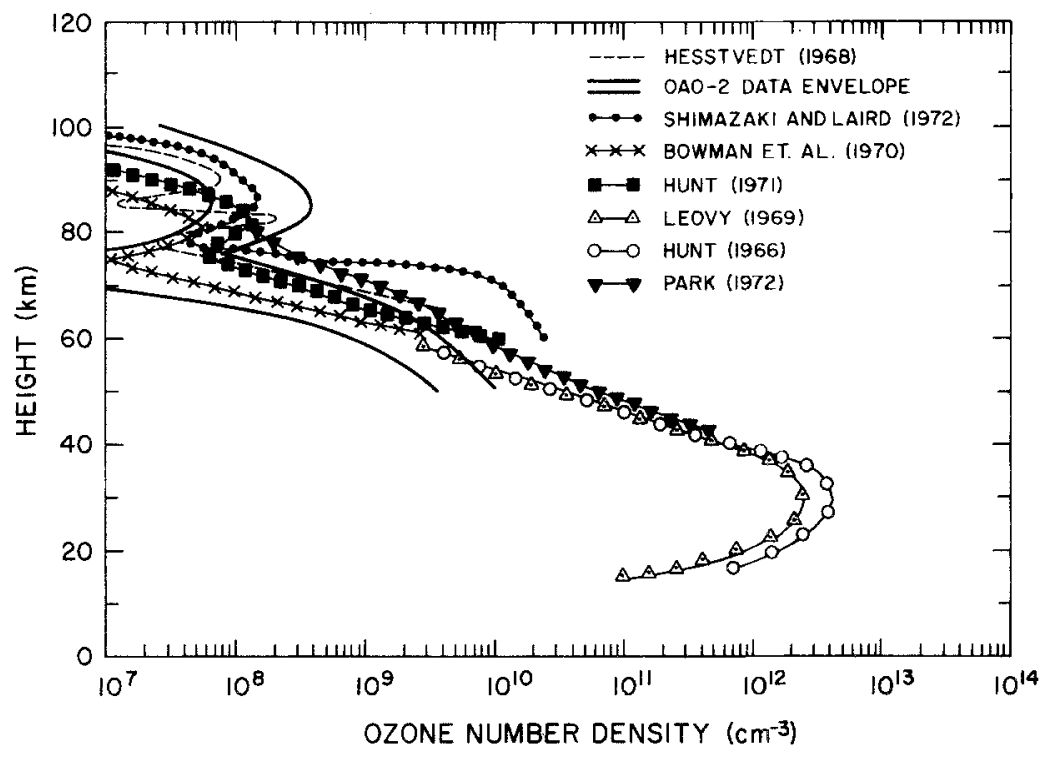

Figure 6

Comparison of the OAO-2 ozone data envelope with the ozone number density profile determined from various theoretical models

density at low signal levels in the presence of statistical noise. ROBLE and HAYS [22] show that the ozone number density is best retrieved between normalized occultation data values of $0.1-0.9$. Therefore, the ozone number density profile determined from the OAO-2 occultation measurements are limited to the $60-95 \mathrm{~km}$ altitude interval. In Fig. 6 the OAO-2 ozone data envelope is also compared with the ozone number density profile determined from various theoretical models. In general, there is a large variation between the various theoretical models. However, the general features of the OAO-2 ozone measurements appear to be present in the results of theoretical predictions which utilize a moist atmosphere in which hydrogen compounds are considered in the chemistry. 


\section{Acknowledgement}

We thank K. S. HANSEN for programming assistance and A. N. SHAH for obtaining the data. This work was supported in part by NASA Grant NGR 23 005-360 and NASA contract NAS 19958. We wish to acknowledge the helpful support of Dr. Houk and the OAO Wisconsin and NASA experimental team.

\section{REFERENCES}

[1] M. ACKerman, Ultraviolet solar radiation related to mesospheric processes, Aeron. Acta. A (1972), No. 77.

[2] M. R. Bowman, L. Thomas and J. E. GeISLER, The effect of diffusion processes on the hydrogen and oxygen constituents in the mesosphere and lower thermosphere, J. Atmos. Terr. Phys. 32(1970), 1661.

[3] J. H. CARVER, B. H. Horton and F. G. BURGER, Rocket determination of the night ozone distribution and the lunar ultraviolet flux, Space Res. 7 (1967), 1020.

[4] J. H. CARVer, B. H. Horton, R. S. O'Brien and B. Rofe, Ozone determinations by lunar rocket photometry, Planetary Space Sci. 20 (1972), 217.

[5] W. F. J. Evans and E. J. Llewellyn, Molecular oxygen emissions in the airglow, Ann. Geophys. $26(1970), 167$.

[6] W. F. J. EVANS and E. J. LLEWELLYN, Measurements of mesospheric ozone from observations of the $1.27 \mu$ band, Radio Sci. 7 (1972), 45 .

[7] W. F. J. EVANS, H. C. WOOD and E. J. LLEWELLYN, Ground-based photometric observations of the $1.27 \mu$ band in the evening twilight, Planetary Space Sci. 18 (1970), 1065.

[8] P. B. HAYs and R. G. RoBLE, Stellar spectra and atmospheric composition, J. Atmos. Sci. 25 (1968a), 1141.

[9] P. B. HAYs and R. G. RoBle, Atmospheric properties from the inversion of planetary occultation data, Planetary Space Sci. 16 (1968b), 1197.

[10] P. B. HAYs and R. G. RoBle, Stellar occultation measurements of molecular oxygen in the lower thermosphere, Planetary Space Sci (1972a), in press.

[11] P. B. HAys and R. G. Roble, Observation of mesospheric ozone at low latitudes, Planetary Space Sci. (1972b), in press.

[12] P. B. HAYs, R. G. Roble and A. N. SHAH, Terrestrial atmospheric composition from stellar occultations, Science 176 (1972), 793.

[13] E. HESSTVEDT, On the effect of vertical eddy transport on atmospheric composition in the mesosphere and lower thermosphere, Geophys. Norv. 27 (1968), 1.

[14] E. HilsenRath, Ozone measurements in the mesosphere and stratosphere during two significant geophysical events, J. Atmos. Sci. 28 (1971), 295.

[15] B. G. HUnt, Photochemistry of ozone in a moist atmosphere, J. Geophys. Res. 71 (1966), 1385.

[16] B. G. HUNT, A diffusion photochemical study of the mesosphere and lower thermosphere and the associated conservation mechanism, J. Atmos. Terr. Phys. 33 (1971), 1869.

[17] C. B. LEOVY, Atmospheric ozone: An analytic model for photochemistry in the presence of water vapor, J. Geophys. Res. 74 (1969), 417.

[18] D. E. Miller and K. H. StewarT, Observations of atmospheric ozone from an artificial earth satellite, Proc. Roy. Soc. London A288 (1965), 540.

[19] J. PARK, Ozone photochemistry and energy budget in the middle atmosphere. Ph.D. thesis, University of Colorado, Boulder, Colorado (1972).

[20] R. D. Rawcliffe, G. E. Meloy, R. M. Friedman and E. H. Rogers, Measurement of vertical distribution of ozone from a polar orbiting satellite, J. Geophys. Res. 68 (1963), 6425.

[21] E. I. REED, A night measurement of mesospheric ozone by observations of ultraviolet airglow, $\mathrm{J}$. Geophys. Res. 73 (1968), 2951. 
[22] R. G. ROBLE and P. B. HAYS, A technique for recovering the vertical number density profile of atmospheric gases from planetary occultation data, Planetary Space Sci. 20 (1972), 1727.

[23] R. G. RoBle and R. B. NORTON, Thermospheric molecular oxygen from solar EUV occultation measurements, J. Geophys. Res. 77 (1972), 3524.

[24] T. SHIMAZAKI and A. R. LAIRD, Seasonal effects on distributions of minor neutral constituents in the mesosphere and lower thermosphere, Radio Sci. 7 (1972), 23.

[25] G. C. Trsone, Measurements of the absorption of solar radiation by $\mathrm{O}_{2}$ and $\mathrm{O}_{3}$ in the 2150-A region, J. Geophys. Res. 77 (1972), 2971.

[26] L. H. WEEKS and L. G. SMITH, A rocket measurement of ozone near sunise, Planetary Space Sci. $16(1968), 1189$. 